\title{
KELANJUTAN PENGEMBANGAN NUKLIR IRAN DI ERA PEMERINTAHAN BARU AMERIKA SERIKAT
}

\author{
CONTINUATION OF IRAN'S NUCLEAR DEVELOPMENT IN THE ERA OF THE NEW \\ GOVERNMENT OF THE UNITED STATES
}

\author{
Riksa Nafis Alamsyah \\ Program Studi Hubungan Internasional Universitas Singaperbangsa Karawang \\ E-mail : 2010631260042@ student.unsika.ac.id
}

\begin{abstract}
ABSTRAK
Iran merupakan salah satu negara yang mengembangkan teknologi nuklir di Timur Tengah. Pengembangan nuklir ini bertujuan untuk perdamaian dunia dan sudah dikembangkan sejak tahun 1953 dengan dukungan dari Amerika Serikat. Iran sempat mengembangkan senjata nuklir yang mana itu tidak diperbolehkan. Hingga pada tahun 2015, dibentuklah suatu perjanjian untuk mengatur pengembangan nuklir ini bersama negara $5 \mathrm{P}+1$. Perjanjian mengatur dan mengawasi pengembangan nuklir Iran agar tidak membelot dari tujuannya. Pada tahun 2018, Amerika Serikat mundur dari perjanjian ini dan menjatuhkan sanksi kembali kepada Iran. Sanksi yang dijatuhkan berupa sanksi ekonomi yang membuat ekonomi Iran terpuruk. Amerika Serikat berharap Iran mau menuruti apa yang diinginkan Amerika Serikat. Nyatanya, sanksi tersebut membuat Iran menjadi out of control dari sebagaimana seharusnya. Pada awal tahun 2021, pemerintahan Amerika Serikat diambil alih oleh Joe Biden. Diketahui, Joe Biden ingin bergabung kembali kedalam perjanjian JCPOA. Sampai saat ini, belum ada kepastian tentang kelanjutan keinginan Joe Biden dan pengembangan nuklir Iran itu sendiri.
\end{abstract}

Kata Kunci: Iran, Nuklir, JCPOA

\begin{abstract}
Iran is one of the countries developing nuclear technology in the Middle East. This nuclear development aims for world peace and has been developed since 1953 with the support of the United States. Iran has developed nuclear weapons which it is not allowed. Until 2015, an agreement was formed to regulate this nuclear development with $5 P+1$ countries. The agreement regulates and oversees Iran's nuclear development so as not to deviate from its goals. In 2018, the United States withdrew from this agreement and reimposed sanctions on Iran. The sanctions imposed are in the form of economic sanctions that make the Iranian economy slump. The United States hopes Iran will do what the United States wants. In fact, the sanctions made Iran out of control than it should be. In early 2021, the United States government was taken over by Joe Biden. It is known, Joe Biden wants to rejoin the JCPOA agreement. Until now, there is no certainty about the continuation of Joe Biden's wishes and Iran's nuclear development itself
\end{abstract}

Keywords: Iran, Nuclear, JCPOA 


\section{PENDAHULUAN}

Iran adalah salah satu dari banyak negara di dunia yang mengembangkan teknologi nuklir. Pengembangan ini sudah berlangsung sejak tahun 1953 dibawah kepemimpinan Shah Mohammad Reza, dengan dukungan penuh dari Amerika Serikat, sebuah kesepakatan ditandatangani dibawah program Atom for Peace. Kemudian, pada tahun 1959, dibawah arahan AEOI (Atomic Energy Organization of Iran) pusat penelitian nuklir didirikan di Universitas Teheran dan resmi didirikan pada tahun 1967. Amerika Serikat mendukung penuh pengembangan nuklir Iran ini, pada tahun 1967 Amerika Serikat mensuplai bahan Uranium dan Plutonium untuk kelanjutan pengembangan nuklir ini (Sundari, 2020). Pengembangan nuklir Iran ini tidak berjalan dengan mudah begitu saja, banyak sekali pro dan kontra adanya pengembangan nuklir ini. Ketika Presiden Amerika Serikat, George Walker Bush melabeli Iran sebagai poros kejahatan, Pernyataan itu menimbulkan kekhawatiran internasional tentang program nuklir Iran (Sinaga, 2009). Proyek pengembangan nuklir ini dituduh bertujuan untuk tujuan senjata pemusnah massal. Oleh karena itu, pengembangan ini menjadi suatu perbincangan serius mengenai keamanan dunia khususnya wilayah Timur Tengah. Proyek nuklir merupakan salah satu tujuan Presiden Iran Mahmoud Ahmadinejad untuk lebih fokus pada urusan dalam negeri Iran. Salah satu bukti nyata adalah pengayaan uranium dalam upaya meningkatkan kekayaan dan mengurangi kemiskinan. Dengan demikian, pada tahun 2015, dicapai kesepakatan mengenai pengembangan nuklir Iran yang dikenal dengan Joint Comprehensive Plan Of Action (JCPOA) yang disepakati dengan negosiasi diplomatik beberapa negara, antara lain Amerika Serikat, Inggris, Perancis, Rusia, China, Jerman dan tentu saja Iran. Alasan dibuatnya kesepakatan ini dikarenakan kecurigaan negara adikuasa yaitu Amerika Serikat yang menuduh bahwasannya Iran menyalahgunakan pengembangan nuklirnya untuk dijadikan senjata pemusnah massal (Satwika Paramasatya, 2019). Pada tahun 2016 Donald Trump resmi terpilih menjadi Presiden Amerika Serikat setelah Presiden Obama. Tentunya kebijakan-kebijakan yang sudah ada berubah sesuai dengan kepemimpinan yang baru. Tepat tiga tahun setelah perjanjian JCPOA ditandatangani, Amerika Serikat secara resmi menarik diri dari perjanjian tersebut dan memberlakukan kembali sanksi terhadap Iran yang dituduh mengembangkan senjata nuklir.

\subsection{Rumusan Masalah}

Pengembangan nuklir Iran menimbulkan banyak sekali pro dan kontra. Kegaduhan terjadi saat Presiden George Walker Bush bahwa Iran adalah negara axis of evil. Kecurigaan 
terhadap Iran pun muncul dan menduga adanya pengembangan senjata nuklir yang dilakukan oleh Iran. Karena ada dugaan tersebut, dibentuklah perjanjian JCPOA pada tahun 2015 yang bertujuan untuk mengatur pengembangan nuklir ini dan diawasi langsung oleh IAEA. Pada tahun 2018, Amerika Serikat secara sepihak menarik diri dari perjanjian yang dipimpin oleh Donald Trump. Donald Trump mengatakan ada yang salah dengan kesepakatan itu. Sebelum keluar, Amerika Serikat melakukan pertemuan untuk membahas apa yang salah dengan perjanjian tersebut. Apabila kesalahan tersebut dapat direvisi, maka Amerika Serikat akan tetap dalam perjanjian. Namun, tidak ada revisi dari perjanjian tersebut yang pada akhirnya Amerika Serikat menarik diri dan menjatuhkan sanksi kepada Iran. Sanksi-sanksi tersebut berupa sanksi ekonomi yang bertujuan untuk melumpuhkan Iran dan berharap Iran akan mematuhi apa yang diinginkan Amerika Serikat. Tetapi, pada kenyataanya Iran justru semakin menentang Amerika Serikat dan tetap mengembangkan nuklirnya.

\section{TINJAUAN LITERATUR}

\subsection{Teori Realisme}

Realisme mengasumsikan bahwa manusia dan negara secara inheren egosentris dan agresif. Inilah sebabnya mengapa politik internasional adalah arena perebutan kekuasaan. (Hadiwinata, 2017). Dalam situasi anarkis, maka masing-masing negara harus memperjuangkan kelangsungan hidupnya melalui pembangunan kekuatan militer. Perilaku manusia terhadap satu sama lain didasarkan pada tiga asumsi dasar. Pertama, manusia pada dasarnya sama. Kedua, manusia bebas bertindak sendiri dengan berinteraksi satu sama lain dalam situasi anarki. Ketiga, dalam situasi anarki, orang biasanya didorong oleh dorongan untuk bersaing, saling intrik, dan keinginan untuk mengalahkan orang lain. Bagi realisme, tugas utama negara adikuasa dalam system bipolar adalah menjaga balance of power dengan cara membangun kekuatan militer untuk mencegah adanya perang. (Hadiwinata, 2017)

\subsection{Konsep Keamanan}

Keamanan merupakan sebuah consested concept, kaum realisme menganggap konsep keamanan secara singkatnya adakah keadaan bebas dari ancaman militer yang berasal dari lingkungan eksternal. Ada juga definisi lain bahwa keamanan hadir ketika masyarakat terbebaskan dari kemiskinan dan ketakutan. Keamanan juga berkaitan dengan emosi yang menggerakan dan dapat dieksploitasi melalui sekuritisasi (Rachman, 2017). Kapabilitas suatu 
negara diharuskan ditingkatkan untuk mempertahankan diri dari ancaman-ancaman dari lingkungan eksternal. Menurut Barry Buzan, keamanan tidak hanya bidang militer saja. Melainkan ada 5 bidang lain yaitu: militer, politik, lingkungan, ekonomi, dan societal (Buzan, 1991).

\section{METODOLOGI PENELITIAN}

Metode penilitian adalah metode ilmiah untuk memperoleh data untuk menjelaskan, membuktikan, mengembangkan, dan mencari pengetahuan dengan tujuan dapat dipahami dan menantisipasi suatu masalah (Sugiyono, 2012). Adapun metode penelitian untuk penulisan jurnal ini adalah metode kualitatif dengan Teknik studi literatur dan internet searching. Metode ini digunakan untuk memahami secara dalam tentang kelanjutan pengembangan nuklir sebagai upaya detterence Iran ditengah ancaman Amerika Serikat. Studi literatur adalah merupakan penelitian yang dilakukan oleh peneliti dengan mengumpulkan berbagai buku, jurnal, majalah yang berkaitan dengan masalah dan tujuan penelitian (Warsiah, 2009). Pengumpulan data studi literatur melibatkan tiga proses penting, yaitu: editing, organizing, finding.

1. Editing, adalah pemeriksaan berulang dari data yang diperoleh, terutama dalam hal kelengkapan, kejelasan makna dan konsistensi makna.

2. Organizing adalah mengorganisir data yang diperoleh dengan kerangka yang diperlukan.

3. Finding adalah melakukan analisis lebih lanjut dari hasil sistematisasi data dengan menggunakan aturan, teori, dan metode yang telah ditentukan sebelumnya untuk menarik kesimpulan yang merupakan hasil jawaban dari rumusan masalah.

Adapun penggunaan teknik internet searching dalam penelitian ini adalah untuk memudahkan pencarian data yang dibutuhkan untuk penelitian ini. Internet searching adalah pencarian menggunakan computer yang dilakukan melalui internet dengan alat atau perangkat lunak yang ditelusuri melalui server-sever diseluruh dunia (Sarwono, 2006). Agar data memiliki kredibilitas yang tinggi, tentunya dibutuhkan dokumen atau data yang otentik. Data-data yang digunakan berasal dari tulisan-tulisan terdahulu yang sudah ada (Awwaabiin, 2021). 


\section{HASIL DAN PEMBAHASAN}

Sejak tahun 1953 dibawah pimpinan Shah Muhammad Reza, Iran mengembangkan teknologi nuklirnya. Dengan bantuan dan dukungan penuh dari Amerika Serikat, tentunya memudahkan Iran dalam pengembangan ini. Dibangunnya pusat penelitian, mendatangkan para ahli, dan menyuplai bahan-bahan dasar untuk nuklir adalah bukti yang konkret dukungan Amerika Serikat terhadap Iran. Tetapi, pengembangan nuklir ini menjadi sebuah perbincangan dan menjadi fokus masyarakat internasional. Dikarenakan adanya rumor ditambah dengan pernyataan dari Presiden Amerika Serikat George Walker Bush pada tahun 2002 dalam sebuah pidato yang menyebutkan bahwasannya Iran adalah poros kejahatan (Axis Of Evil) beserta Iraq, dan Korea Utara. Pernyataan ini membuat kecurigaan terhadap Iran (Sinaga, 2009).

\subsection{Amerika Serikat dan Perjanjian JCPOA}

Amerika Serikat mencurigai adanya pengembangan senjata nuklir yang dilakukan oleh Iran. Maka dari itu, dibuatlah sebuah perjanjian yaitu Joint Comprehensive Plan of Action (JCPOA) yang merupakan perundingan diplomatik yang dibentuk oleh Amerika Serikat, Inggris, Perancis, Rusia, Tiongkok, Jerman, dan Iran pada tahun 2015. Kesepakatan ini dibuat untuk mengawasi pengembangan nuklir Iran karena sebelum ada perjanjian tersebut, Iran sempat membelot dan mengembangkan senjata nuklir. Tetapi, perjanjian ini hanya bertahan selama tiga tahun bagi Amerika Serikat. Karena pada tahun 2018 Presiden Amerika Serikat Donald Trump mencabut perjanjian JCPOA juga resmi menarik diri dari perjanjian tersebut dan kembali memberlakukan sanksi kepada Iran atas tuduhan pengembangan senjata nuklirnya. Amerika Serikat kembali menjatuhkan sanksi kepada Iran atas tuduhan ini berupa sanksi ekonomi yang diharapkan dapat menghentikan Iran mengembangkan nuklirnya.

Keluarnya Amerika Serikat tentunya didasari oleh beberapa hal yang memberatkan Amerika Serikat dibawah pimpinan Presiden Donald Trump untuk tetap didalam perjanjian tersebut. Ada 3 hal yang membuat Amerika Serikat keluar dari perjanjian JCPOA, yaitu kegagalan untuk mengatasi program rudal balistik Iran, persyaratan dimana inspektur internasional dapat mengunjungi situs nuklir Iran yang dicurigai, dan klausa "sunset" yang mana batasan perjanjian JCPOA ini berakhir setelah 10 tahun setelah perjanjian itu dibuat (Arshad Mohammed, 2018). Sebenarnya, pada bulan Januari 2018 Presiden Donald Trump mengajak sekutu Eropanya untuk memperbaiki apa yang menurut pemerintahan Donald 
Trump salah dengan JCPOA. Donald Trump pun bersedia untuk tetap dalam perjanjian apabila kesalahan-kesalahan dalam perjanjian JCPOA dapat diatasi. Beberapa pemimpin negara seperti Presiden Perancis Emmanuel Macron dan Kanselir Jerman Angela Merkel melakukan kunjungan ke Amerika Serikat untuk berdiskusi dan meyakinkan Presiden Donald Trump agar tetap dalam perjanjian JCPOA, namun kunjungan tersebut tidak berbuah hasil apapun (Wildan Ilmanuarif Shafar, 2020). Walaupun begitu, kekuatan politik Iran memberikan dorongan untuk terus mengembangkan nuklirnya dan bersikeras pengembangan nuklirnya ini untuk tujuan perdamaian dunia.

Bagi Amerika Serikat, pengembangan ini tidak boleh dilanjutkan karena akan menganggu stabilitas keamanan di Timur Tengah, khususnya Israel yang merupakan negara aliansi Amerika Serikat (Sundari, 2020). Pemerintahan Trump percaya kesepakatan itu tidak cukup untuk membatasi pengembangan senjata nuklir Iran dan tidak dapat meredam Iran dalam mengkritik keamanan dan stabilitas di Timur Tengah. (Wildan Ilmanuarif Shafar, 2020). Letak Amerika Serikat dan Iran yang tidak dekat tentu membuat ancaman keamanan bagi Amerika Serikat tidaklah begitu besar, tetapi dikarenakan negara aliansi Amerika Serikat berada di wilayah Timur Tengah tentunya Amerika Serikat mempertimbangkan keamanan negara aliansinya tersebut (Wildan Ilmanuarif Shafar, 2020). Israel adalah salah satu negara di wilayah Timur Tengah yang khawatir akan keamanannya karena pengembangan nuklir Iran ini. Iran menjadi sebuah negara yang mengancam dominasi Amerika Serikat dan sekutunya yaitu Israel di Timur Tengah. Tentunya, pengembangan ini menjadi kekhawatiran mereka karena ditakutkan akan menjadi pesaing yang dapat mendominasi di Timur Tengah (Sundari, 2020). Maka dari itu, alasan Amerika Serikat mendesak dan mengancam Iran untuk menghentikan pengembangan nuklirnya adalah desakan dari Israel itu sendiri sebagai negara sekutu dari Amerika Serikat. Ketakutan Israel sudah tidak aneh apabila Iran tetap melanjutkan pengembangan nuklirnya. Dominasi Israel di Timur Tengah dapat dikalahkan oleh dominasi Iran dengan nuklirnya. Jika dibandingkan kekuatan militernya saja, kekuatan Iran jauh lebih kuat dibandingkan Israel.

Sebagai negara yang beraliansi dengan Israel, sudah patutnya Amerika Serikat memperhatikan keamanan negara aliansinya tersebut. Dilain sisi juga, tentunya tidak hanya Israel saja yang terancam apabila Iran mengembangkan senjata nuklir. Keamanan Iran juga menjadi terancam apabila tidak ada titik terang kegaduhan ini. Iran harus mengupayakan deterrence agar keamanan negaranya terjamin dari negara-negara yang mengancamnya. 
Detterence akan tercapai apabila 3 hal dapat dipenuhi, yaitu komitmen, kapabilitas, dan kredibilitas (Spiegel, 2004).

(1) Komitmen

Negara berkomitmen akan "menghukum" negara lain yang berani melakukan serangan kepada negara yang bersangkutan. Dibutuhkan Langkah yang definitive dan spesifik untuk menekankan komitmen ini

(2) Kapabilitas

Detterence adalah meyakinkan negara lain bahwasannya apabila negara lain melakukan kesalahan seperti menyerang, maka negara harus memiliki kekuatan untuk menyerang balik negara penyerang.

(3) Kredibilitas

Kredibilitas ini membantu negara dalam melaksanakan atau memenuhi komitmen dan membangun kapabilitas hingga akhirnya upaya penangkalan atau deterrence dapat berjalan baik sebagaimana mestinya.

Deterrence secara singkat adalah bagaimana menumbuhkan "rasa" musuh enggan atau takut untuk menyerang. Pengembangan nuklir inilah salah satunya sebagai upaya deterrence Iran untuk menjaga keamanan negaranya. Karena suatu negara akan berpikir kembali apabila ingin menyerang ke negara yang memiliki teknologi nuklir. Setiap negara yang memiliki kekuatan nuklir, memiliki resiko lebih kecil untuk diserang, bahkan hanya memiliki fasilitasnya saja. (Buzan, 1991). Selain kekuatan nuklirnya, Iran sendiri memilki jangkauan rudal terbesar dan paling beragam di Timur Tengah. Menurut laporan CSIS, rudal tersebut memiliki jangkauan yang jauh, dan rudal Iran dapat mencapat beberpa bagian Asia Tenggara dan Eropa (CSIS Missile Defense Project, 2020). Keluarnya Amerika Serikat dari perjanjian JCPOA menjadi suatu hal yang bertabrakan antara ekspektasi Amerika Serikat terhadap Iran dan apa yang justru Iran lakukan. Ketika Amerika Serikat masih tergabung di perjanjian JCPOA, Iran justru mematuhi dan menjalankan kesepakatannya sesuai aturan yang ada dalam perjanjian tersebut. Tetapi, disaat Amerika Serikat keluar dari perjanjian tersebut, berdasarkan inspeksi IAEA justru Iran melakukan pelanggaran lagi pasca Amerika Serikat keluar dari perjanjian JCPOA. Hal itu dilakukan Iran karena Iran merasa kecewa akan keputusan Amerika Serikat yang keluar dari perjanjian yang sudah disepakati bersama. 


\subsection{Kebijakan Donald Trump Terhadap Iran Pasca Keluar dari JCPOA}

Kebijakan yang dikeluarkan Presiden Donald Trump pasca mengundurkan diri dari JCPOA adalah memberlakukan kembali sanksi-sanksi kepada Iran. Sanksi-sanksi yang dikeluarkan Presiden Donald Trump kepada Iran berupa sanksi ekonomi yang tentunya memberatkan Iran khususnya disektor ekonomi Iran. Sebelumnya sanksi-sanksi tersebut dicabut ketika dibentuknya perjanjian JCPOA. Salah satu sektor terpenting Iran adalah minyak yang menurun karena sanksi yang dilemparkan Amerika Serikat. tentunya Ketika sumber pendapatan berkurang, maka perkembangan ekonomi juga ikut memburuk. Tingkat perekonomian suatu negara mempengaruhi kemampuannya untuk mencapai tujuannya (Kegley, 2009). Suatu negara akan lebih aktif dalam politik dunia karena ada kepentingan yang harus didapat ketika ekonomi maju.

Mundurnya Amerika Serikat dari perjanjian JCPOA menjadi suatu hal yang tidak begitu berpengaruh bagi Amerika Serikat. Karena Amerika Serikat memiliki kapasitas ekonomi yang kuat dan tidak memiliki ketergantungan terhadap Iran, maka tidak masalah bagi Amerika Serikat untuk keluar dari JCPOA. Bahkan apabila Iran memberi sanksi terhadap Amerika Serikat dan harus menutup bisnis-bisnis milik Amerika Serikat di Iranpun tidak akan berpengaruh apa-apa (Wildan Ilmanuarif Shafar, 2020). Sebenarnya, sanksi-sanksi ini dibuat bertujuan agar Iran menuruti apa yang diinginkan Amerika Serikat. AS ingin Iran meninjau kembali program nuklirnya dan lainnya. Sebelumnya Amerika Serikat mengumumkan kebijakan bernama Significant Reduction Exceptions (SREs) yang melibatkan beberapa negara seperti India, China, Jepang, Korea Selatan, Yunani, Turki, Taiwan, dan Italia sebagai pengimpor minyak Iran. Negara-negara tersebut dilarang membeli minyak dari Iran untuk menekan ekspor minyak Iran k enol atau export to zero. Apabila negara-negara tersebut mencoba untuk tetap mengimpor minyak dari Iran, maka Amerika Serikat akan menjatuhkan sanksi juga untuk negara-negara tersebut. Tetapi, pada 2 Mei 2019 kebijakan ini tidak diperpanjang dan semua pelayaran dengan pengiriman sesuai dengan SREs yang ada harus diselesaikan dalam batas waktu sampai 2 Mei 2019. Maka dari itu, pengangkutan minyak Iran setelah 2 Mei 2019 akan diberlakukan sebagai pelanggaran sanksi Amerika Serikat dengan resiko yang terkait (UKP\&I, 2020). 


\subsection{Respon Iran Terhadap Amerika Serikat}

Tentunya, kebijakan-kebijakan yang dikeluarkan oleh Amerika Serikat tidak membuat Iran menerima begitu saja. Iran merespon atas kebijakan-kebijakan yang dibuat oleh Amerika Serikat. Setelah Amerika Serikat keluar dari perjanjian JCPOA, hubungan antara Amerika Serikat dan Iran menjadi tegang. Seperti yang sudah disebutkan sebelumnya, ketika Amerika Serikat keluar dari perjanjian Iran menjadi agresif dan bertindak lebih mengecam. Iran melakukan kembali ancaman pengembangan nuklirnya akan tetap berlanjut. IAEA menyatakan Iran memperkaya pengayaan uranium melebihi batas seharusnya sesuai perjanjian. Krisis kesepakatan nuklir ini semakin dalam karena Amerika Serikat memberlakukan sanksi yang menghilangkan manfaat yang seharusnya dinikmati Iran sebagai imbalan karena menyetujui perjanjian JCPOA (Beaumont, 2019). Sanksi Amerika Serikat terbukti mampu melumpuhkan perekonomian Iran, tetapi tidak efektif untuk menghentikan Iran mengembangkan nuklirnya. Keputusan Amerika Serikat dibawah kepemimpinan Donald Trump ini menjadi keputusan yang membuat Iran semakin tidak terkontrol. Sampai saat ini, pengembangan nuklir Iran masih berlanjut. Diketahui, Iran siap untuk bekerja sama dengan negara-negara islam untuk pengembangan nuklir ini. Hal ini disampailan oleh juru bicara AEOI Behrouz Kamalvandi saat melakukan kunjungan ke Reaktor Riset Shahid Fakhrizadeh di Teheran dalam rangka Islamic Unity Week (Sindonews, 2021).

\subsection{Amerika Serikat dan Nuklir Iran di Era Joe Biden}

Setelah masa kepemimpinan Presiden Donald Trump berakhir pada 20 Januari 2021. Kepemimpinan Amerika Serikat berhasil diambil alih oleh Joe Biden sebagai Presiden Amerika Serikat yang baru. Diketahui, Joe Biden sudah lama ingin Amerika Serikat bergabung kembali ke perjanjian JCPOA (Tempo, 2021). Namun, meurut Kerry, pengabaian Amerika terhadap implikasi moral dari kepercayaan Iran pada Amerika akan berkurang (Aljazeera, 2018). Karena itu, Iran tidak akan dengan mudah percaya akan keinginan Amerika Serikat yang ingin bergabung kembali dalam perjanjian JCPOA. Pemimpin Tertinggi Iran, Ayatollah Ali Khamenei menyeru komitmen Amerika Serikat untuk bergabun kembali kedalam perjanjian JCPOA. Amerika Serikat diminta untuk mencabut sanksi-sanksi yang dijatuhkan Amerika Serikat kepada Iran dalam waktu sepekan. Keinginan Amerika Serikat ingin bergabung kembali dalam perjanjian JCPOA adalah berharap dapat mengontrol 
dan membuat Iran patuh kembali peraturan dalam perjanjian yang sudah ada. Tetapi, dalam sepekan itu, tidak ada langkah apapun yang diambil dari dua negara tersebut (Tempo, 2021).

Sampai saat ini, Joe Biden masih mengupayakan untuk kembali bergabung dalam perjanjian JCPOA. Joe Biden berusaha melakukan diplomasi kepada Iran agar bersedia menjalin perjanjian nuklir kembali. Apabila diplomasi tersebut gagal, maka Joe Biden akan mengambil langkah lain (BBC News, 2021). Pemerintahan Joe Biden berpendapat bahwasannya keluar dari perjanjian JCPOA dan menjatuhkan sanksi terhadap Iran hanya mendorong Iran untuk mengembangkan nuklirnya sebagai senjata (France24, 2021). Seperti apa yang sudah terjadi di lapangan, pendapat pemerintahan Joe Biden dapat dibenarkan dengan fakta yang ada. Kekecewaan Iran terhadap Amerika Serikat sepertinya masih belum padam. Karena Amerika Serikat yang pada tahun 2018 keluar dari perjanjian nuklir Iran, 4 tahun setelahnya ingin bergabung kembali kedalam perjanjian tersebut. Hal ini lah yang menjadi diplomasi antara Amerika Serikat dan Iran menjadi "alot”. Pada tanggal 30 Oktober 2021, Presiden Joe Biden dan tiga pemimpin Eropa bertemu dan share tentang pengembangan nuklir Iran. Mereka mengirim sinyal yang jelas ke Iran bahwa mereka siap untuk kembali ke kesepakatan JCPOA. Mereka sangat yakin bahwa Amerika Serikat dapat segera bergabung dan patuh terhadap peraturan yang ada untuk memastikan bahwa program pengembangan nuklir Iran ini adalah untuk tujuan perdamaian. Pembicaraan antara Amerika Serikat dan Iran untuk kembali kedalam perjanjian terhenti sejak bulan juni. Ketika kepemimpinan Iran diambil alih oleh Ebrahim Raisi, Iran siap untuk melakukan negosiasi kembali.

\section{KESIMPULAN}

Perkembangan nuklir Iran ini menjadi banyak sekali perbincangan dari berbagai negara, terutama Amerika Serikat. Perbincangan ini menjadi tegang karena dugaan adanya pengembangan senjata pemusnah massal. Semenjak Amerika Serikat menarik diri dari perjanjian JCPOA dibawah kepemimpinan Donald Trump, Iran menjadi negara yang tidak terkontrol dalam pengembangan nuklirnya. Pengayaan uranium tercatat sudah melebihi batas dari yang seharusnya. Iran menjadi agresif setelah Amerika Serikat menarik diri dari JCPOA dan memberlakukan kembali sanksi terhadap Iran. Sanksi-sanksi yang dijatuhkan kepada Iran bertujuan agar Iran mau menuruti dan patuh kepada Amerika Serikat tentang pengembangan nuklirnya. Tetapi, nyatanya sanksi-sanksi ini tidak begitu efektif. Walaupun sanksi-sanksi 
tersebut memberatkan ekonomi Iran, tetapi tidak dapat membuat Iran patuh terhadap Amerika Serikat. Sampai saat ini, pengembangan masih berlanjut. Diketahui Iran siap untuk bekerja sama dengan negara islam untuk pengembangan nuklir ini. Bergantinya kepemimpinan Amerika Serikat oleh Joe Biden tentunya akan menjadi era baru bagi Amerika Serikat. Dikabarkan, Joe Biden sedang mengupayakan diplomasi ke Iran agar dapat bergabung kembali kedalam perjanjian JCPOA. Pertemuan G20 yang diadakan di Roma menjadi salah satu langkah kesiapan Amerika Serikat untuk bergabung kembali ke perjanjian JCPOA. Mereka percaya dan memastikan bahwa perjanjian JCPOA adalah untuk perdamaian dan sanksi-sanksi yang dijatuhkan akan dicabut untuk pertumbuhan ekonomi Iran.

\section{DAFTAR PUSTAKA}

\section{Buku:}

[1] Buzan, B. (1991). People States and Fear, 2nd edition. New York: Harvester Whearsheaf.

[2] Griffiths, M. T. (2002). International Relations the Key Concepts 2nd. London: Routledge.

[3] Hadiwinata, B. S. (2017). Studi dan Teori Hubungan Internasional: Arus Utama, Alternatif, dan Reflektivis. Jakarta: Yayasan Pustaka Obor Indonesia.

[4] Kegley, C. \&. (2009). The Global Future: A Brief Introduction to World Politics 3rd Edition. Boston: Wadsworth Publishing.

[5] Sugiyono. (2012). Memahami Penelitian Kualitatif. Bandung: ALFABETA.

[6] Sarwono, J. (2006). Metode Penelitian Kuantitatif dan Kualitatif. Yogyakarta: Graha Ilmu.

[7] Spiegel, S. L. (2004). World Politics in a New Era. United States.

[8] Warsiah, D. E. (2009). Metode Penulisan Karya Ilmiah. Bandung: Laboratorium Pendidikan Kewarganegaraan.

\section{Jurnal:}

[1] Aljazeera. (2018, Mei 09). Retrieved from aljazeera.com: www.aljazeera.com/news/2018/5/9/world-leadersreact-to-us-withdrawal-from-iraniannuclear-deal

[2] Rachman, A. B. (2017). EDITORIAL: Keamanan Internasional. 5.

[3] Satwika Paramasatya, S. W. (2019). Konfrontasi Amerika Serikat dan Iran dalam Joint Comprehensive Plan of Action. 19. 
[4] Sinaga, O. (2009). Kepemilikan Nuklir dan Keamanan Nasional Iran: Suatu Studi Kasus. 19.

[5] Sundari, R. (2020). Strategi Amerika Serikat Dalam Menekan Pengembangan Nuklir Iran. 29.

[6] Wildan Ilmanuarif Shafar, D. M. (2020). Resistensi Hubungan Luar Negeri Amerika Serikat dan Iran: Studi Kasus Joint Comprehensive Plan of Action (JCPOA), 32.

\section{Sumber Online:}

[1] Arshad Mohammed, J. I. (2018, April 13). Progress in Iran deal talks, but Trump stance uncertain. Retrieved from www.reuters.com: www.reuters.com/article/us-iran-nucleardiplomat-idUSKBN1HJ38G

[2] Awwaabiin, S. (2021, June 7). Studi Literatur: Pengertian, Ciri-ciri, dan Teknik Pengumpulan Datanya. Retrieved from penerbitdeepublish.com: penerbitdeepublish.com/studi-literatur/

[3] Beaumont, P. (2019, Juli 08). Iran Has Enriched Past Key Limit IAEA Confirms. Retrieved from The Guardian Web Site: www.theguardian.com/world/2019/jul/08/iranhas-enriched-past-key-limit-iaea-confirms

[4] Biden administration 'in a difficult position' in effort to rejoin Iran nuclear deal. (2021, 05 08). Retrieved from France24 Website: https://www.france24.com/en/americas/20210508-biden-administration-in-a-difficultposition-in-effort-to-rejoin-iran-nuclear-deal

[5] Iran Minta Joe Biden Buktikan Komitmen Kembali ke Perjanjian Nuklir. (2021, Februari 18). Retrieved from Tempo Website: dunia.tempo.co/read/1433908/iran-minta-joebiden-buktikan-komitmen-kembali-ke-perjanjian-nuklir/full\&view=ok

[6] Iran nuclear: Other options if diplomacy fails, says Biden. (2021, 08 27). Retrieved from BBC News Website: www.bbc.com/news/world-middle-east-58315818

[7] Iran Sanctions Update: Significant Reduction Exemptions. (2020, 03 11). Retrieved from UKP\&I Web Site: https://www.ukpandi.com/news-and-resources/articles/2019/iransanctions-update-significant-reduction-exemptions/

[8] Missile of Iran. (2020, July). Retrieved from CSIS Missile Defense Project: https://missilethreat.csis.org/country/iran

[9] Sindonews. (2021, oktober 24). Iran Siap Bekerja sama dengan Dunia Islam dalam Pengembangan Nuklir. Retrieved from Sindonews: https://international.sindonews.com/read/577952/43/iran-siap-bekerja-sama-dengandunia-islam-dalam-pengembangan-nuklir-1635048630 